\title{
The strength of compressed structures with CFRP materials reinforcement when exceeding the cross-section size
}

\author{
Petr Polskoy ${ }^{1}$, Dmitry Mailyan ${ }^{1}$, Sergey Georgiev ${ }^{1}$, Viktor Muradyan ${ }^{1 *}$ \\ ${ }^{1}$ Don State Technical University, Rostov-on-Don
}

\begin{abstract}
The increase of high-rise construction volume or «High-Rise Construction» requires the use of high-strength concrete and that leads to the reduction in section size of structures and to the decrease in material consumption. First of all, it refers to the compressed elements for which, when the transverse dimensions are reduced, their flexibility and deformation increase but the load bearing capacity decreases. Growth in construction also leads to the increase of repair and restoration works or to the strengthening of structures. The most effective method of their strengthening in buildings of «High-Rise Construction» is the use of composite materials which reduces the weight of reinforcement elements and labour costs on execution of works. In this article the results of experimental research on strength and deformation of short compressed reinforced concrete structures, reinforced with external carbon fiber reinforcement, are presented. Their flexibility is $\lambda \mathrm{h}=10$, and the crosssection dimensions ratio $\mathrm{b} / \mathrm{h}$ is 2 , that is 1,5 times more, than recommended by standards in Russia. The following research was being done for three kinds of strained and deformed conditions with different variants of composite reinforcement. The results of the experiment proved the real efficiency of composite reinforcement of the compressed elements with sides ratio equal to 2 , increasing the bearing capacity of pillars till 1,5 times. These results can be used for designing the buildings of different number of storeys.
\end{abstract}

\section{Introduction}

The growth of capital construction in Russia and abroad extremely requires the use of new modern building materials and structures. Primarily it should be directed to the increase of efficiency and durability of construction structures.

A new push in development of the construction industry and science is come from the «High-Rise Construction» and also from the need of using new kinds of constructive decisions. The more there is an increase of construction, the more there are repair and reconstruction costs of existing and newly erected buildings. Structures restoration is impossible without their strenthening, that is why the composite materials have been included into new and promising materials.

\footnotetext{
${ }^{*}$ Corresponding author: muradyan2007@yandex.ru
} 
Taking into account the above mentioned, the Department of Reinforced Concrete and Stone Structures at Don State Technical University (DSTU) has been investigating and developing new innovative and energy saving technologies in the construction and the improvement of culculations for more than 10 years.

Among such scientific works are: the high-strength concrete and their design features study [1,2]; effective structures with the use of self-sealing high-strength and light concretes on porous aggregates $[3,4]$; prestressed elements with variable prestressing by element length [5,6]; reinforced concrete structures study, strengthened by composite materials with different kinds of tensely-deformed conditions.

The latest works are the strengh study of normal and oblique sections of bending elements at different percentages of external composite reinforcement [7,8]. The third way is the determination of strength and stiffness of compressed reinforced concrete elements with different variants of external longitudinal and transverse reinforcement, and also with different eccentricity of load applications.

The Set of Rules, published in Russia in 2004, about strengthening of reinforced concrete structures with composite materials made the design issues legal. However, the first publication of this Set of Rules couldn't solve many other problems, because according to $[9,10]$, many of its provisions are based on foreign authors' researches, for example, on Aprile's results of research and others [11], concerning the strength issues of oblique sections on the transverse force. The same happens with strengthening of compressed reinforced concrete elements. It is connected with the dimensions ratio of elements sections of rectangular profile $(b / h)$, which cannot be more than 1,5 . The flexibility value of strengthened elements $\lambda_{\mathrm{i}}=\mathrm{l}_{0} / \mathrm{i}$ is limited and cannot exceed 50 . However, a large number of structures or their elements, existed in Russia, still exceeds these constraints. This refers, for example, to compressed pillars and braces in reinforced concrete girders, and also deadbolts of girders' structures and others.

There is not any advice on calculating the compressed elements for which the eccentricity of load application is out of inequality limits $0,3 \mathrm{~h} \leq \mathrm{e}_{0} \leq 0,1 \mathrm{~h}$. However, it is this variant of a strained deformed state which occurs during the construction of high-rise buildings. The following article is of an experimental nature and deals with test results of bearing capacity of short pillars $\left(\lambda_{h}=10\right)$ with sides ratio $(b / h)=2,0$ with three values of eccentricity of load application $\left(\mathrm{e}_{0}=0 ; \mathrm{e}_{0}=0,16 \mathrm{~h} ; \mathrm{e}_{0}=0,32 \mathrm{~h}\right)$ and with different ways and variants of their strengthening with the usage of carbon fiber reinforced plastic.

The final purpose of the work is the proposal development of reliable normative base creation for strenghtened structures calculations using non-traditional materials at any kinds of strained-deformed state.

\section{Materials and methods}

The following investigations were carried out using rectangular test pieces made of heavy concrete of B30-35 class which is often used in the construction nowadays.

For getting comparable results of testing, all the short pillars had similar cross-section $250 \times 125(\mathrm{~h})$ and length $1200 \mathrm{~mm}$. The least of the section size was taken as the height of the pillars (h) to guarantee knowingly a planned destruction including a case of stability loss.

For heavy concrete of $\mathrm{B} 30$ project class, the unfraction crushed stone made of dense limestone 5-20mm, of 800 brand was used. For concrete of B35 class the granite crushed stone of the same fraction of 1000 brand was used.

As a working armature in cross-section of pillars, 4Ø12A500 was used. Knitted cross reinforcement, set with a pace of $180 \mathrm{~mm}$, was accepted with a diameter of $6 \mathrm{~mm}$ made of steel of B 500 class. To prevent concrete crushing under the steel head, on the end sections 
of the carcasses additionally with a pace $50 \mathrm{~mm} 6$ constructive grids made B 500 with a diameter of $4 \mathrm{~mm}$. The size of the cells $50 \times 40 \mathrm{~mm}$.

For elements strengthening two types of external composite reinforcement - transverse and longitudinal were used. For transverse reinforcement three-layer holders or holders with gaps - clamps made from carbon fiber reinforced cloth with unidirectional fibers of cold hardening (MBRACE FIB CF 300/4900.300g/5.100m). The longitudinal reinforcement is represented by laminate - the stripes of unidirectional fibers of hot hardening (MBRACE ${ }^{\circledR}$ LAM CF210/2400.50x1,4.100m). Both types of carbon fiber reinforced plastic are made in Germany.

By test results according to the State Standard 25.601-80 the test strength indicators for three-layer carbon fiber reinforced cloth made $\sigma_{f, u} 2888,8 \mathrm{MPa}$ and coincides with the standardized technical characteristics of the manufacturer's factory.

All the pillars strengthened by the carbon fiber reinforced plastic were tested at the age of 680-720 days. After strenthening with composite materials the sample before the moment of their testing were kept during 10-15 days.

\section{Results}

As it was mentioned above, at the first stage of studying the compressed reinforced concrete elements strengthened by composite materials, 16 test short $(\lambda \mathrm{h}=10)$ pieces were investigated. In the process of testing three eccentricity values of load application $(\mathrm{e} 0=0$; $\mathrm{e} 0=2,0 ; \mathrm{e} 0=4,0 \mathrm{~cm}$ ) and nine variants of external reinforcement were varied. The structure of all strengthening variants is represented in picture 1. Here you also can see the cross sections and the pace of transverse clamps.

It is necessary to mention separately, that all the pillars near the metal heads had design three-layer clamps at $100 \mathrm{~mm}$ wide. For elements with external transverse composite reinforcement these clamps played the role of anker increasing the reliability of its anchoring.

The results of the conducted experiment on the strength of the test pieces are represented in Table 1. For easy using there is an index number of a piece together with its pressmark. Besides, having the natural inaccuracy of concrete strength, the results of the experiment were analyzed taking into account the strength of samples but not the destructive efforts (Column 4). Their bearing capacity $N_{s, f}^{\text {red }}$ was obtained by means of multiplication the test destructive load by the coefficient $k_{s, f}^{r e d}$, equal to concrete classes of standard and strengthened samples.

Simultaneously for increasing the reliability of the experiment's results, separate strengthened samples which showed little strength in each series of tests were included into the standard samples. These samples in Table 4 are marked with *. This value is indicated in the denominator of column 6.

The method of direct comparison of strengthening the reinforced samples $-N_{s, f}^{\text {red }}$, and standard samples $-\bar{N}_{s, f}^{\text {red }}$ was taken as the main method of the efficiency assessment of different variants of strengthening. Their ratio is named the coefficient of strength $-k_{s, f}^{r e d}$. 
a)

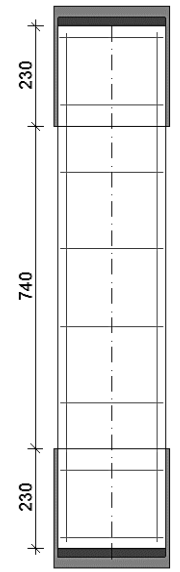

AK

b)

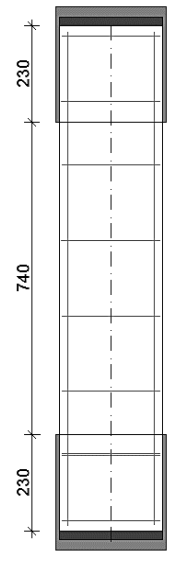

BK

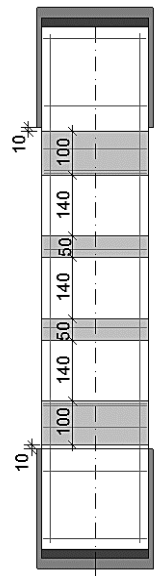

AKY-X

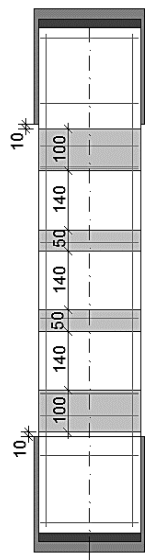

BKY-X

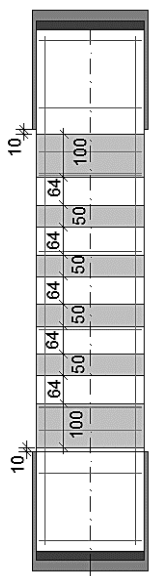

$\mathrm{AKY}-\mathrm{X}_{6}$

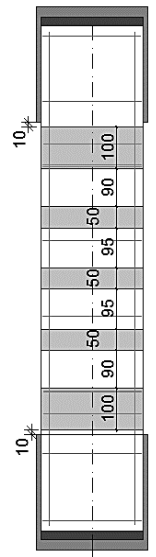

$\mathrm{BKY}-\mathrm{X}_{2}$

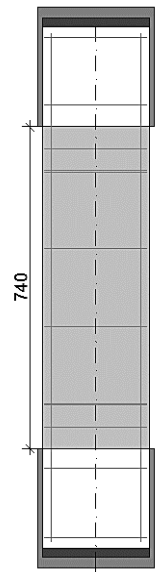

$\mathrm{AKY}-\mathrm{X}_{5}$
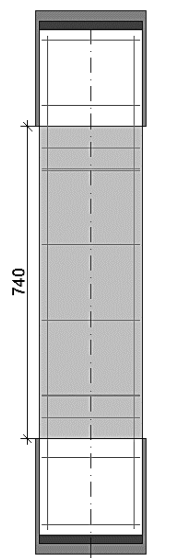

BKY- $\mathrm{X}_{5}$

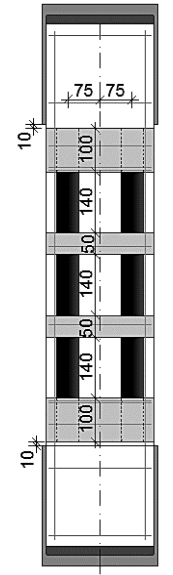

AKY $-X_{1} L_{a} \quad A K Y-X_{1} R_{a}$

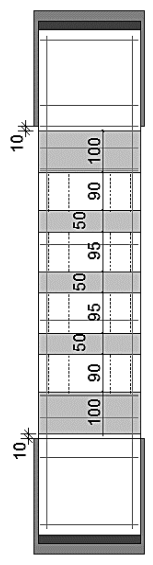

$\mathrm{BKY}-\mathrm{X}_{2} \mathrm{~L}_{\mathrm{c}}$
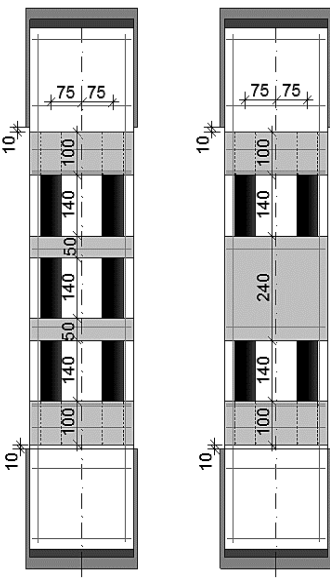

$\mathrm{CKY}-\mathrm{X}_{1} \mathrm{~L}_{\mathrm{p}} \quad \mathrm{CKY}-\mathrm{X}_{3} \mathrm{~L}_{\mathrm{p}}$
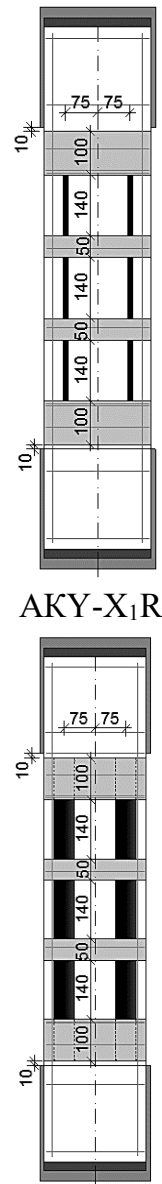

$\mathrm{BKY}-\mathrm{X}_{1} \mathrm{~L}_{\mathrm{p}}$

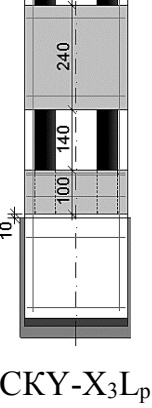

c)
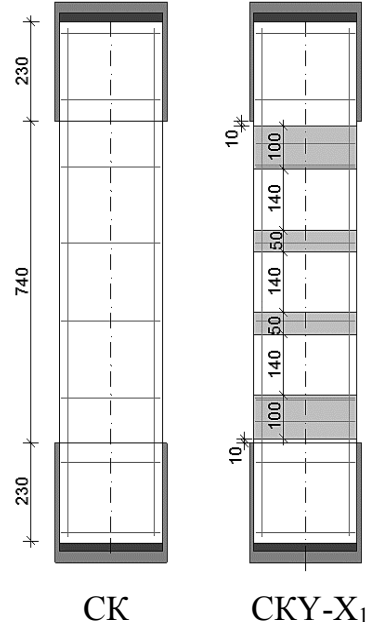

Fig. 1. Variants of strengthening the short $\left(\lambda_{h}=10\right)$ pillars of external transverse and longitudinal reinforcement with eccentricity of load application $\mathrm{e}_{0}=0-(\mathrm{a}) ; \mathrm{e}_{0}=2 \mathrm{~cm}-(\mathrm{b})$; $\mathrm{e}_{0}=4-$ (c). 


\section{Analysis}

Data analysis in Columns 6-9 of Table 1showed the following:

The pillars stregthened by reinforced three-layer holder with the variant $\mathrm{X}_{5}$, tested with eccentricity $\mathrm{e}_{0}=0$, showed maximum bearing capacity. Specifically it can be seen by its actual value of load growth $\Delta N_{s, f}^{r e d}$ for strengthened pillars. With eccentricity $\mathrm{e}_{0}=2,0 \mathrm{~cm}$ $(0,16 \mathrm{~h})$ the efficiency of the entire holder reduced 2 times.

The second effective variant is $\mathrm{X}_{1} \mathrm{R}_{\mathrm{L}}$, in which the strenthening is done with circle bars $\varnothing 8 \mathrm{~mm}$, pasted into the groove, cut in the protective layer of the concrete. The same picture is in the studies [12], where instead of circle bars the stripes of $25 \mathrm{~mm}$ wide and of 1,4 $\mathrm{mm}$ thick were put into the groove.

The clamps of transverse reinforcement of $\mathrm{w}_{f}=50 \mathrm{~mm}$ wide had three different paces in axis $-\mathrm{S}_{f}=190 ; 140 ; 125 \mathrm{~mm}$. Evaluating the influence of the gap size equal to $140 ; 95$; $65 \mathrm{~mm}$ respectively (Picture 2), it can be noted that there was no strong influence on the change of bearing capacity of pillars, strengthened by these variants $\left(\mathrm{X}_{1}, \mathrm{X}_{2}, \mathrm{X}_{6}\right)$.

With eccentricity $\mathrm{e}_{0}=2,0 \mathrm{~cm}(0,16 \mathrm{~h})$ in our experiments the clamps $\mathrm{X}_{1}$ and $\mathrm{X}_{2}$ showed a load growth for short pillars, comparable with an effect of the entire holder.

The clamps in variant $\mathrm{X}_{3}$ had an increasing effect only in the complex variant of strengthening together with external longitudinal complex reinforcement.

Table 1. Comparison of the following test strength of standard and reinforced short pillars by changing the variants of external composite reinforcement.

\begin{tabular}{|c|c|c|c|c|c|c|c|c|}
\hline \multirow[b]{3}{*}{$\begin{array}{l}\text { № of } \\
\text { pillars }\end{array}$} & \multirow[b]{3}{*}{$\begin{array}{l}\text { Pressmark } \\
\text { of pillars }\end{array}$} & \multirow[b]{3}{*}{$\begin{array}{l}\text { Class of } \\
\text { concrete } \\
B, \mathrm{MPa}\end{array}$} & \multirow{2}{*}{\multicolumn{2}{|c|}{ Test load (кN): }} & \multicolumn{4}{|c|}{ The given values: } \\
\hline & & & & & \multicolumn{2}{|c|}{ Strength (кN): } & \multirow[b]{2}{*}{$\begin{array}{c}\text { Load } \\
\text { growth } \\
(\kappa \mathrm{N}) \\
\Delta N_{s, f}^{\text {red }}\end{array}$} & \multirow{2}{*}{$\begin{array}{l}\begin{array}{l}\text { Coefficient } \\
\text { of strength }\end{array} \\
k_{s, f}^{r e d}=\frac{N_{f}^{r e c}}{\bar{N}_{s}^{r e c}}\end{array}$} \\
\hline & & & \begin{tabular}{|c} 
At \\
destructi \\
on \\
$N_{s}, N_{s f}$
\end{tabular} & $\begin{array}{c}\text { At maximum } \\
\text { permissible } \\
\text { deformation } \\
N_{\Delta, u l t}\end{array}$ & $\begin{array}{c}\text { At } \\
\text { destructi } \\
\text { on } \\
N_{s} ; N_{s f}^{r e d}\end{array}$ & $\begin{array}{c}\text { At maximum } \\
\text { permissible } \\
\text { deformation } \\
N_{\Delta, \text { ult }}^{\text {red }}\end{array}$ & & \\
\hline 1 & 2 & 3 & 4 & 5 & 6 & 7 & 8 & 9 \\
\hline \multicolumn{9}{|c|}{ Series A. Axial eccentricity $\mathrm{e}_{0}=0$} \\
\hline 1 & AK & 33,2 & 1150 & 1500,0 & 1150,0 & 1150,0 & - & 1,0 \\
\hline $2 *$ & $\mathrm{AKY}-\mathrm{X}_{1}$ & 30,0 & 1190,5 & 1190,5 & 1317,5 & 1317,5 & 112,2 & 1,093 \\
\hline \multirow{2}{*}{$5 *$} & \multirow{2}{*}{$\begin{array}{l}\mathrm{AKY}- \\
\mathrm{X}_{1} \mathrm{~L}_{\mathrm{a}}\end{array}$} & \multirow{2}{*}{31,8} & \multirow{2}{*}{1100,0} & \multirow{2}{*}{1100,0} & 1148,4 & 1148,4 & \multirow[t]{2}{*}{ - } & \multirow{2}{*}{1,0} \\
\hline & & & & & 1205,3 & 1205,3 & & \\
\hline 3 & $\mathrm{AKY}-\mathrm{X}_{6}$ & 39,3 & 1600,0 & 1600,0 & 1351,6 & 1351,6 & 146,3 & 1,12 \\
\hline 4 & $\mathrm{AKY}-\mathrm{X}_{5}$ & 30,1 & 1625,0 & 1625,0 & 1792,3 & 1792,3 & 587,0 & 1,487 \\
\hline 1 & 2 & 3 & 4 & 5 & 6 & 7 & 8 & 9 \\
\hline 6 & $\begin{array}{l}\text { AKY- } \\
X_{1} R_{a}\end{array}$ & 30,1 & 1379,0 & 1379,0 & 1521,0 & 1521,0 & 315,7 & 1,262 \\
\hline \multicolumn{9}{|c|}{ Series B. Axial eccentricity $\mathrm{e}_{0}=2 \mathrm{~cm}(0,16 \mathrm{~h})$} \\
\hline 7 & BK & 30,3 & 592,5 & 545,0 & 592,5 & 545,0 & - & 1,0 \\
\hline \multirow{2}{*}{$12 *$} & \multirow{2}{*}{$\begin{array}{l}\mathrm{BKY}- \\
\mathrm{X}_{1} \mathrm{~L}_{\mathrm{p}}\end{array}$} & \multirow{2}{*}{31,8} & \multirow{2}{*}{700,0} & \multirow{2}{*}{630,0} & 667,06 & 600,3 & \multirow[t]{2}{*}{37,3} & \multirow{2}{*}{1,06} \\
\hline & & & & & 629,7 & 572,65 & & \\
\hline 8 & $\mathrm{BKY}-\mathrm{X}_{1}$ & 30,0 & 778,9 & 685,0 & 786,7 & 691,85 & 157,0 & 1,249 \\
\hline
\end{tabular}




\begin{tabular}{|c|c|c|c|c|c|c|c|c|}
\hline 9 & $\mathrm{BKY}-\mathrm{X}_{2}$ & 30,3 & 794,7 & 700,0 & 794,7 & 700,0 & 165,0 & 1,262 \\
\hline 10 & $\mathrm{BKY}-\mathrm{X}_{5}$ & 32,4 & 844,0 & 750,0 & 789,3 & 701,4 & 159,6 & 1,253 \\
\hline 11 & $\begin{array}{l}\mathrm{BKY}- \\
\mathrm{X}_{2} \mathrm{~L}_{\mathrm{c}}\end{array}$ & 32,4 & 800,0 & 730,0 & 748,1 & 682,7 & 118,4 & 1,188 \\
\hline \multicolumn{9}{|c|}{ Series C. Axial eccentricity $\mathrm{e}_{0}=4 \mathrm{~cm}(0,32 \mathrm{~h})$} \\
\hline 13 & $\mathrm{CK}$ & 33,2 & 422,2 & 335,0 & 422,2 & 335,0 & - & 1,0 \\
\hline \multirow{2}{*}{$14 *$} & \multirow{2}{*}{ CKY-X 1} & \multirow{2}{*}{33,2} & \multirow{2}{*}{482,5} & \multirow{2}{*}{380,0} & 482,5 & 380,0 & \multirow[t]{2}{*}{330,2} & \multirow{2}{*}{1,067} \\
\hline & & & & & 452,3 & 357,5 & & \\
\hline 15 & $\begin{array}{l}\text { CKY- } \\
X_{1} L_{p}\end{array}$ & 33,2 & 530,0 & 435,0 & 530,0 & 435,0 & 77,7 & 1,172 \\
\hline 16 & $\begin{array}{l}\text { CKY- } \\
\mathrm{X}_{3} \mathrm{~L}_{\mathrm{p}}\end{array}$ & 39,4 & 608,0 & 455,0 & 512,3 & 383,4 & 60,0 & 1,133 \\
\hline
\end{tabular}

It should be noted, that the efficiency of transverse clamps influence, pasted on the longitudinal elements of external reinforcement, reduces and appears regardless the eccentricity value.

The longitudinal external reinforcement of short pillars with the usage of laminate at $\mathrm{e}_{0}=0$ and $2,0 \mathrm{~cm}$ did not influence on their bearing capacity because this armature went wrong when loaded within $(0,75-0,8) \mathrm{N}_{\text {ult }}$. The similar results were got in the work [13]. With eccentricity $\mathrm{e}_{0}=4,0 \mathrm{~cm}$ the laminate (stripes), pasted on the extended face, on the contrary, showed the positive effect. It is well conformed with the regulations $[14,15]$.

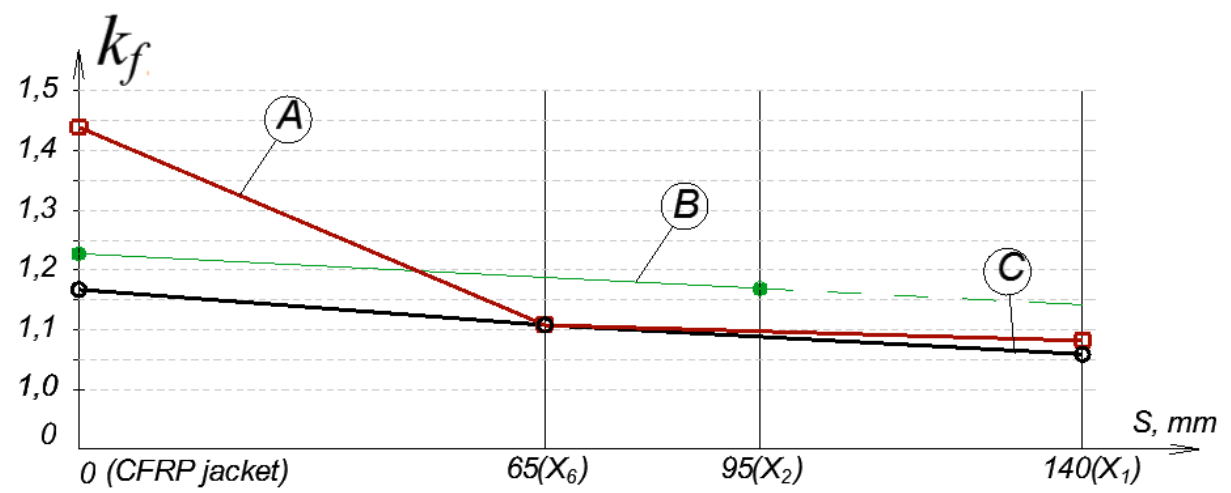

Fig. 2. The influence of the gap value between clamps (S) on the efficiency of three-layer transverse reinforcement of short pillars $\left(\lambda_{\mathrm{h}}=10\right)$ with eccentricity of load application $\mathrm{e}_{0}=0$ (A); $\mathrm{e}_{0}=2,0 \mathrm{~cm}(\mathrm{~B}) ; \mathrm{e}_{0}=4,0 \mathrm{~cm}(\mathrm{C})$. 


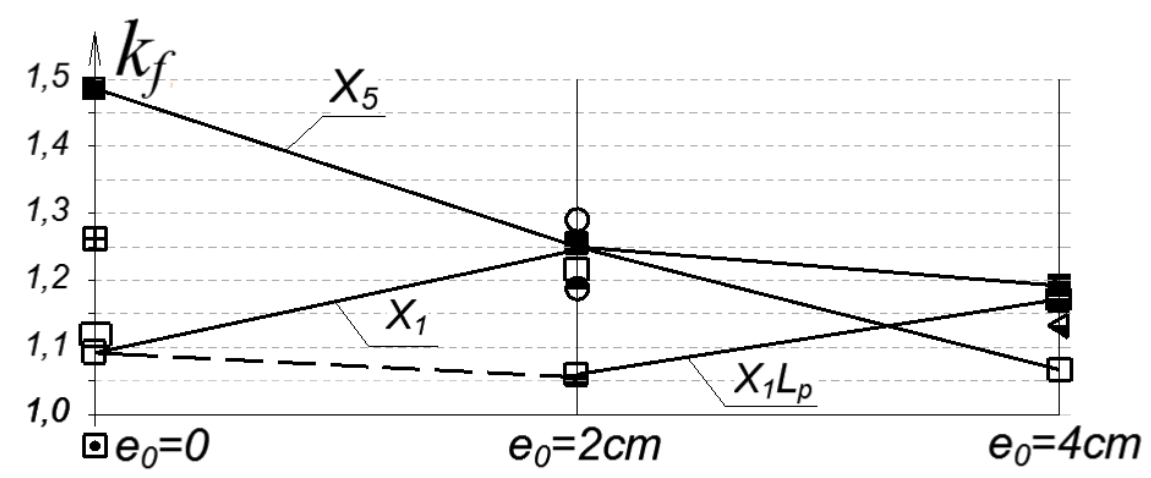

Fig. 3. The influence of eccentricity of load application on the change of the coefficient of composite strength $\left(k_{f}^{\text {red }}\right)$ of short pillars. Conventions are done in Table 2.

Table 2. Conventions for Picture 2 and Picture 3.

\begin{tabular}{|c|c|c|c|c|c|c|c|c|}
\hline $\begin{array}{c}\text { Variant of } \\
\text { strengthening }\end{array}$ & 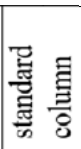 & 茫 & $\begin{array}{l}x \\
\dot{x} \\
i\end{array}$ & $\underset{\nu}{\vec{x}}$ & $\underset{\sim}{\stackrel{0}{x}}$ & $\frac{\overbrace{}^{2}}{\bar{x}^{\prime}}$ & $\underbrace{\infty}_{-1}$ & $\begin{array}{l}x^{\pi} \\
\bar{x} \\
\bar{x}\end{array}$ \\
\hline $\begin{array}{l}\text { Conventions of } \\
\text { variants of the } \\
\text { strengthening }\end{array}$ & & & & 0 & & & & $\boxplus$ \\
\hline
\end{tabular}

All mentioned above about the influence of variants of strengthening on the bearing capacity of test samples can be seen if we analyze the graphics in Picture 3, where the change of test values of the composite strength coefficient $k_{s f}^{\text {red }}$ is shown, depending on the eccentricity of the load application.

It is important to note again that according to our experiments the efficiency of transverse reinforcement reduces a bit if the clamps are pasted on the longitudinal stripes laminates of external strengthening. Apparently, it can be explained by the fact that the cocrete can easily be deformed in the transverse direction in the intersection places between longitidinal and transverse composite armatures. It also happens, in our opinion, because of less tight fit of clamps to concrete and absence of full adhesion in the places of clamps intersection (made of cloth) and elements of longitudinal reinforcement (from stripes of laminates) because different pasted compositions are used for these materials. Besides, it is necessary to put extra repair composition to prevent height difference at the intersection of strengthening elements.

\section{Conclusions}

1) The conducted experimental research of compressed reinforced concrete elements with the sides ratio $\mathrm{b} / \mathrm{h}=2$ with the flexibility $\lambda_{h}=10$, strengthened with carbon fiber reinforced plastic in transverse and longitudinal directions and tested with axial eccentricity of load application $\mathrm{e}_{0}=0 ; \mathrm{e}_{0}=0,16(\mathrm{~h})$ и $\mathrm{e}_{0}=0,32(\mathrm{~h})$, proved not only the possibility but also the high enough efficiency of composite reinforcement.

2) It was established that the strengthening effect in compressed elements by composite materials is achieved not only with eccentricity of load application $\mathrm{e}_{0} \leq 0,1 \mathrm{~h}$ and $\mathrm{e}_{0}>0,3 \mathrm{~h}$, but 
also for compressed elements working with little eccentricity $\mathrm{e}_{0}=0,16 \mathrm{~h}$. The latest are not taken into account.

3) The most reliable for elements loaded at $\mathrm{e}_{0} \leq 0,16 \mathrm{~h}$, is strengthening by complete holders. However, it should be noted that efficiency of composite reinforcement at the similar percent of reinforcement reduces because tension in the elements of strengthening does not achieve calculated resistance and that requires improvement of calculating apparatus.

4) The efficiency of external transverse reinforcement by clamps in the presense of external longitudinal reinforcement at $\mathrm{e}_{0}=0$ reduces at $6-12 \%$. For elements working with big eccentricity $\left(\mathrm{e}_{0}=0,32 \mathrm{~h}\right)$, transverse reinforcement is functional because it increases the reliability of adhesion for external longitudinal composite reinforcement. Its pace must not exceed the value $\mathrm{S}_{\mathrm{fw}} \leq 15 \mathrm{~d}_{\mathrm{s}}$.

5) Symmetric longitudinal reinforcement of a short pillar of internal circle carbon fiber reinforced plastic consisted of 4 bars with diameter of $8 \mathrm{~mm}\left(\mu_{f}=0,64 \%\right)$, pasted in propylene within the thickness of a protective layer of concrete led to the increase of bearing capacity of a test pillar at $31 \%$ with preservation of rigidity similar to nonstrengthened samples, i.e standard.

\section{References}

1. A.M. Mkrtchyan, D.R. Mailyan, Nauchnoe obozrenie. 11, 72-76 (2013)

2. D.R. Mailyan, V.N. Aksenov, N.B. Aksenov, International scientific conference energy management of municipal transpiration facilities and transport EMMFT (2017)

3. A.N. Davidyuk, D.R. Mailyan, G.V. Nesvetaev, Technologies of concrete. 1-2, 57-59 (2011)

4. A. V. Belyaev, G. V. Nesvetaev, D.R. Mailyan, MATEC Web of Conferences. 106, (2017)

5. D.R. Mailyan, R.1. Mailyan, V.H. Khuranov, News of higher education institutions. Construction. 5, 4-11 (2004)

6. V.A. Muradyan, D.R. Mailyan, A.A. Lyapin, V.E. Chubarov, Earth and environmental science 90 (2017)

7. P.P. Polskoy, D.R. Mailyan, D.A. Dedukh, S.V. Georgiev, Global Journal of Pure and Applied Mathematics. 12.2, 1767-1786 (2016)

8. P.P. Polskoy, D.R. Mailyan, A.A. Shilov, Z.A. Meretukov, New technologies. 4, 4448 (2015)

9. T.A. Mukhamediev, D.V. Kuzevanov, Concrete and reinforced concrete. 2, 18-20 (2014)

10. T.A. Mukhamediev, D.V. Kuzevanov, Concrete and reinforced concrete. 6, 20-24 (2013)

11. A. Aprile, A. Benedetti, Proceedings off First Course on FRP applications for R/C elements rehabilitation, Bologna, Italy (2001)

12. N. Chikh, M. Gahmous, R. Benzaid, Proceedings of the World Congress on Engineering, 4 - 6, (2012)

13. S. Matthys, PhD, Ghent University, 345 p. (2000) 
14. ACI 440.2R-02, Guide for the Design and Construction of Externally Bonded FRP Systems for Strengthening Concrete Structures. American Concrete Institute (ACI), Committee 440 (2008)

15. CNR-DT 200/2004, Guide for the Design and Construction of Externally Bonded FRP Systems for Strengthening Existing Structures, Rome (2004) 